\title{
7T clinical cardiovascular MR imaging: initial experience
}

\author{
Hildo J Lamb ${ }^{1 *}$, Linda Van Schinkel ${ }^{1}$, Eleanore Kroner ${ }^{2}$, Pieter J van den Boogaard ${ }^{1}$, Maarten J Versluis ${ }^{1}$, \\ Albert de Roos ${ }^{1}$, Andrew Webb ${ }^{1}$, Hans-Marc J Siebelink ${ }^{2}$ \\ From 15th Annual SCMR Scientific Sessions \\ Orlando, FL, USA. 2-5 February 2012
}

\section{Summary}

Initial 7T Clinical Cardiovascular MR imaging results are presented. Although there are many basic problems that have to be resolved, 7T cardiovascular MRI has high potential for advanced imaging. Clinical practice has to prove what the specific advantages are of highfield cardiovascular MR imaging.

\section{Background}

Recently, high-field 7T MR imaging was introduced. The higher field-strength has potential advantages, mainly related to increased signal-to-noise-ratio. One of the potentially exciting applications may be cardiovascular MR imaging. Cardiovascular MRI requires robust correction for heart motion, breathing motion and correction of field inhomogeneities. Therefore, cardiovascular imaging at high MR field strength has many challenges to be solved. Therefore, the purpose was to assess clinical feasibility of $7 \mathrm{~T}$ cardiovascular MR imaging.

\section{Methods}

Regular clinical patient exams are scheduled weekly at a regular time slot in our 7T MR 'Gorter center'. During the initial phase of protocol development the presence of a dedicated MR physicist and MR technician is required, as well as presence of a cardiovascular radiologist and cardiologist. Clinical cardiovascular MRI was performed using a commercially available human wholebody 7T MRI system (Philips, The Netherlands), vectorECG-gating and a custom-built 13-cm-diameter quadrature double-loop RF transmit-receive surface coil. Standard cardiovascular MR sequences were adapted from

${ }^{1}$ Department of Radiology (C2S), Leiden University Medical Center, Leiden, Netherlands

Full list of author information is available at the end of the article clinical $1.5 \mathrm{~T}$ and $3 \mathrm{~T}$ protocols. Breath-hold cine MR imaging was performed using TE $0.97 \mathrm{~ms}$, TR $4 \mathrm{~ms}$, flip angle 20 , reconstructed pixel size $0.88 \times 0.88 \times 10 \mathrm{~mm}$. Transmitral flow using velocity sensitivity of $150 \mathrm{~cm} /$ sec, TE $2.6 \mathrm{~ms}$, TR $4.6 \mathrm{~ms}$, flip angle 20 , reconstructed pixel size $1.4 \times 1.4 \times 8 \mathrm{~mm}$. Delayed enhancement acquisitions were performed approximately 15 minutes after intravenous administration of $0.1 \mathrm{mmol} / \mathrm{kg}$ Gadolinium (Dotarem, Guerbet) using an inversion-recovery 3D turbo-field echo sequence, TE $1.2 \mathrm{~ms}$, TR $4 \mathrm{~ms}$, flip angle 15 , reconstructed pixel size $1.2 \times 1.2 \times 5 \mathrm{~mm}$. Inversion time was determined with real-time plan scan to null normal myocardial signal. Vessel wall imaging was performed using TE $3.7 \mathrm{~ms}$, TR $12 \mathrm{~ms}$, flip angle 45, reconstructed pixel size $0.3 \times 0.3 \times 2 \mathrm{~mm}$.

\section{Results}

Initial clinical results are presented as a pictorial essay. Examples were acquired in a routine clinical setting. ECG-triggering was effective in about $90 \%$ of patients. See Figure for first clinical $7 \mathrm{~T}$ results.

\section{Conclusions}

7T clinical cardiovascular MR imaging is feasible. Many basic problems still have to be resolved, such as improved ECG-triggering, improved penetration depth of the transmit-receive surface coil, multi-transmit setup, optimalization of inversion pulses for delayed enhancement and vessel wall imaging. Clinical practice has to prove what the advantages are of high-field cardiovascular MR imaging.

\section{Funding}

No disclosures. 


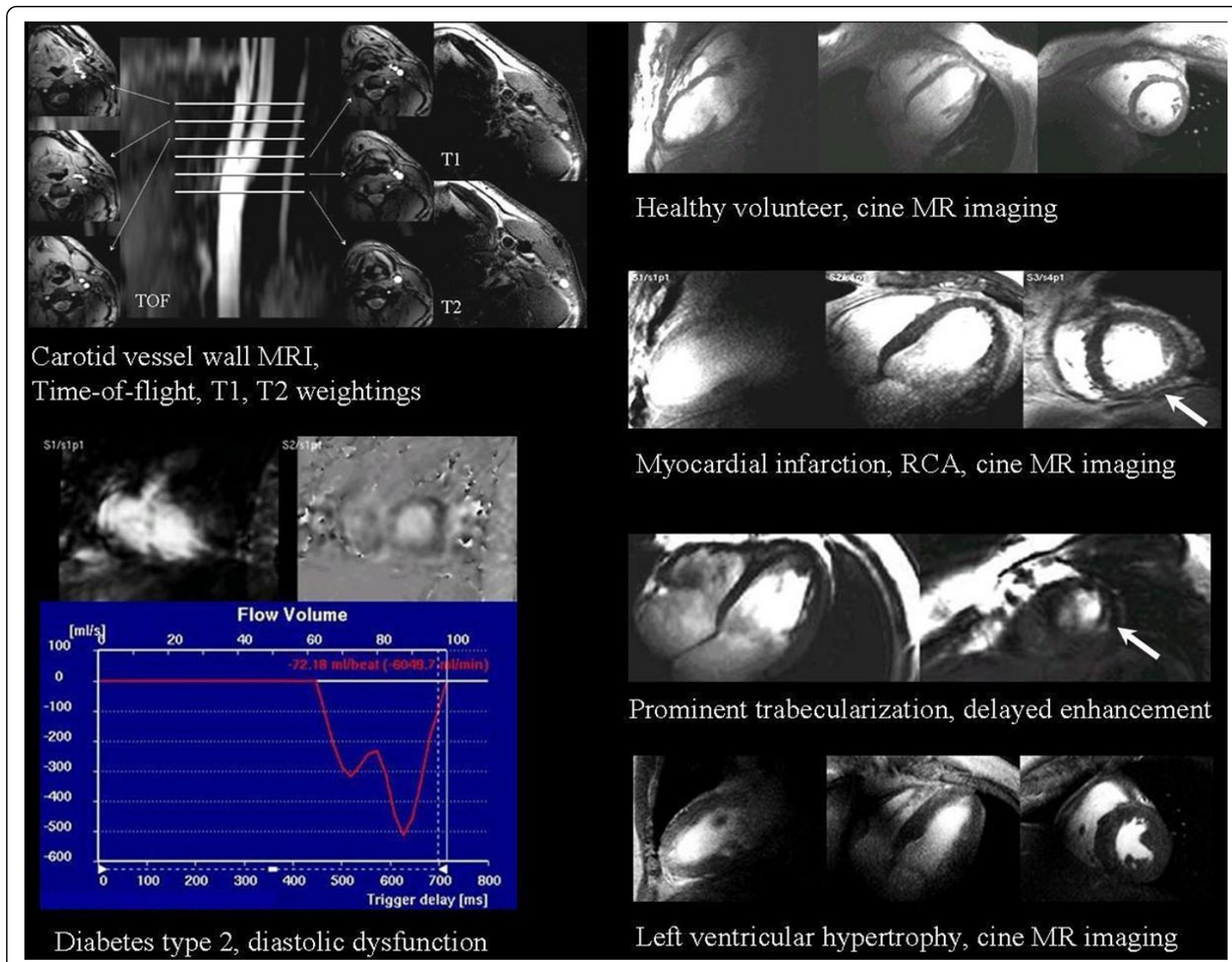

Figure 1 Examples of initial clinical experience with 7T Cardiovascular MR imaging. See text below images for clinical explanation, see abstract text for technical details.

\section{Author details}

${ }^{1}$ Department of Radiology (C2S), Leiden University Medical Center, Leiden, Netherlands. ${ }^{2}$ Cardiology, LUMC, Leiden, Netherlands.

Published: 1 February 2012

\section{doi:10.1186/1532-429X-14-S1-P234}

Cite this article as: Lamb et al:: 7T clinical cardiovascular MR imaging:

initial experience. Journal of Cardiovascular Magnetic Resonance 201214 (Suppl 1):P234
Submit your next manuscript to BioMed Central and take full advantage of:

- Convenient online submission

- Thorough peer review

- No space constraints or color figure charges

- Immediate publication on acceptance

- Inclusion in PubMed, CAS, Scopus and Google Scholar

- Research which is freely available for redistribution 